\title{
ADMINISTRAÇÃO DE INFORMÁTICA E SEUS FATORES CRÍTICOS DE SUCESSO NO SETOR BANCÁRIO PRIVADO NACIONAL
}

\author{
$\star$ Alberto Luiz Albertin \\ albertin@eaesp.fgvsp.br
}

tr Rosa Maria de Moura

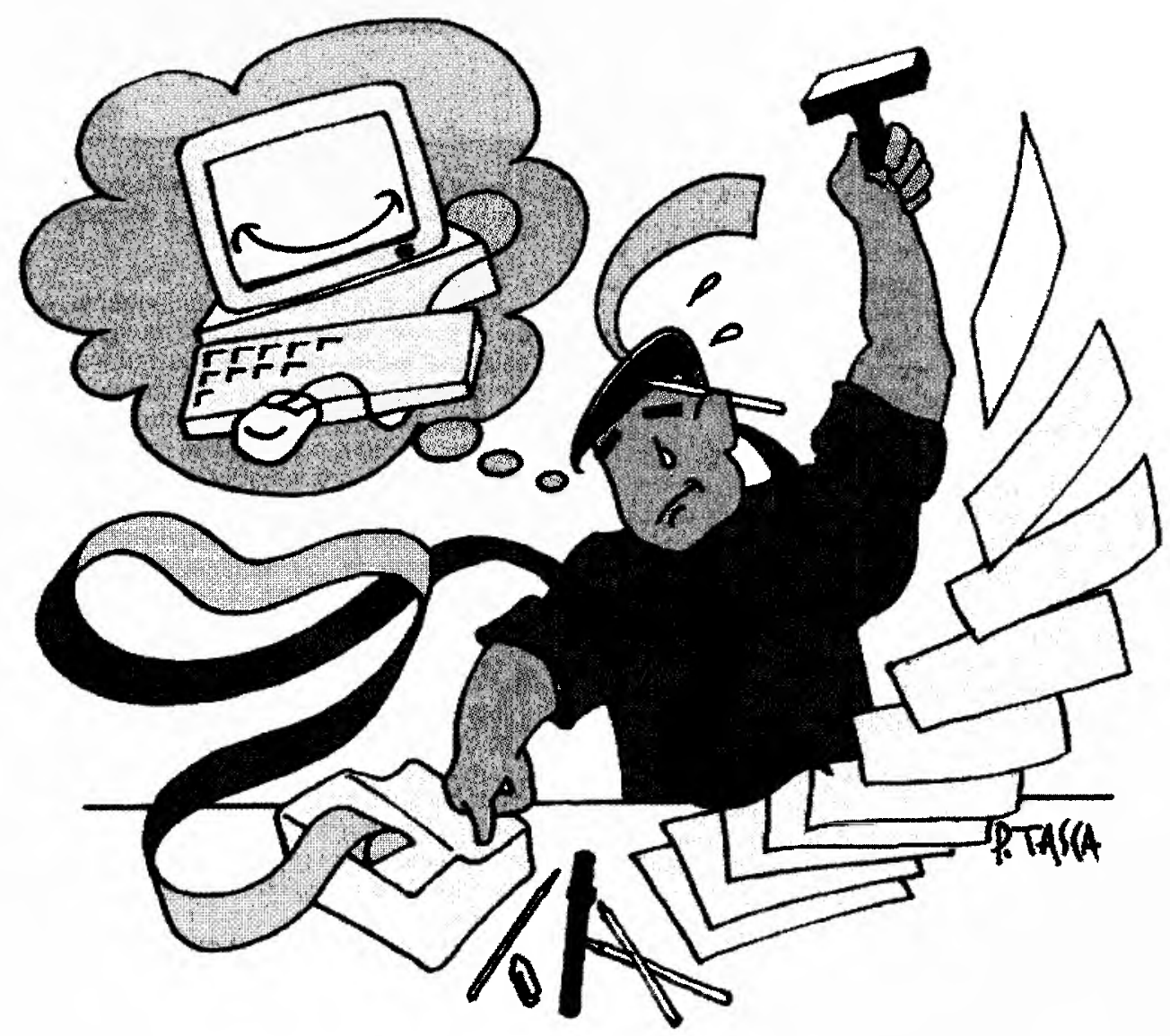

PALAVRAS-CHAVE:

tecnologia da informação, informática, administração de informática em bancos, sistemas de informaçōes, fatores críticos de sucesso, bancos privados, administração bancária, setor bancário, estratégia competitiva.

\section{KEY WORDS:}

information technology, informatics, information technology management in banks, information systems, critical success factors, private banks, bank management, bank sector, competitive strategy.

\section{^ Professor do Departamento de Informática e Métodos Quantitativos da EAESP/FGV e Doutorando em Administração de Empresas na FEAVUSP. \\ ț Mestranda em Administraçáo de Empresas na EAESP/FGV.}

(rae@eaesp.fgvsp.br) Assinatura Email 


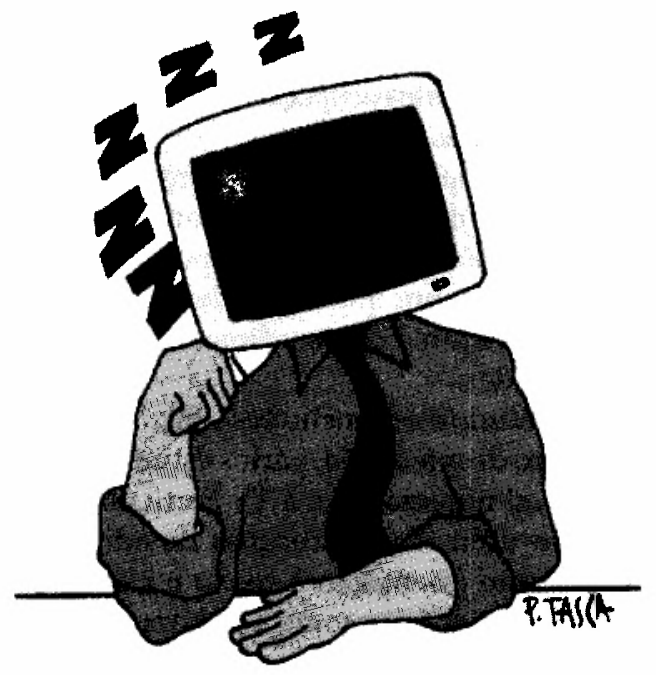

A importância da TI (Tecnologia da Informação) para as organizações é inegável, tanto na sua operacionalização quanto na sua estratégia competitiva. Atualmente, a utilização da TI como arma competitiva tem recebido grande atenção por parte dos executivos das organizações.

Como foi argumentado por Perry ${ }^{1}$, atualmente o SI (Sistema de Informações) tem participado de toda atividade de negócio de uma empresa que oferece um produto ou serviço - desde a concepção, planejamento e produção até a comercialização, distribuição e suporte. Como resultado, o SI tem se tornado um componente crítico do planejamento estratégico corporativo e da vantagem competitiva.

Dada esta visão da importância estratégica da TI, a preocupação essencialmente técnica do seu avanço tem aberto espaço, sem perder o seu próprio, para uma preocupação com a administração da disponibilidade e diversidade tecnológicas, atuais e futuras, alinhando-as com as estratégias organizacionais. Isto contribui para que a preocupação emergente seja de como administrar a informática.

A Administração de Informática não deve apenas considerar os aspectos técnicos de sua função, mas também os sociais. Estes, definidos por Bostrom e Heinen ${ }^{2}$ como o sistema social da teoria sociotécnica, são voltados para o relacionamento entre as pessoas e os seus atributos, tais como atitudes, competências e valores. E as saídas de um sistema de trabalho são o resultado da integração conjunta entre o sistema que considera os as-

\section{O sucesso da Administração de Informática e da própria organização são dependentes da identificação e do tratamento de fatores críticos de sucesso.}

\section{The success of Information Management and of the own organization are dependent on the identification and treatment of critical success factors.}

pectos técnicos e aquele que considera os sociais.

Conforme exposto por Floyd $\mathrm{d}^{3}$ e Earl ${ }^{4}$, entre vários outros trabalhos, o corpo de conhecimento utilizado até então para estudo, pesquisa e prática da Administração de Informática não tem sido suficiente. Uma nova visão está surgindo combinando os corpos de conhecimento sobre SI, estratégia de negócio, comportamento organizacional, gerência de tecnologia e economia industrial.

A Administração de Informática deve considerar tanto seu ambiente interno quanto o externo. Em uma organização privada, ou em uma entidade da administração pública, a Administração de Informática é responsável pela eficácia interna da função informática. Ela é também responsável por garantir o perfeito relacionamento da função com a organização e apoiar esta última na sua operacionalização e estratégia competitiva.

Neste artigo, são analisadas as conclusões do estudo de casos apresentadas por Albertin $^{5}$, onde estão relacionados os FCS (Fatores Críticos de Sucesso) identificados para a Administração de Informática no setor bancário privado nacional.

Como exposto por Rockart ${ }^{6}$, os FCS são as áreas de um negócio nas quais os resultados satisfatórios asseguram um desempenho competitivo bem-sucedido para a organização. Os FCS da Administração de Informática foram analisados com a convicção de que, de modo similar, esta também tem áreas cujos resultados asseguram o desempenho da própria área e desta como componente dos FCS da organização.
1. PERRY, N. 0 . Managing the information systems power. Harvard Business School Bulletin, Boston, v. 62, n. 1, p. 110-22, Feb. 1986

2. BOSTROM, R. P., HEINEN, J. $S$. MIS problems and failures: a social-technical perspective Part II: The Application of sociotechnical theory. MIS Quarterly, Minneapolis, p. 11-28, Dec. 1977

3. FLOYD, C. Outline of a paradigm change in software engineering. Software Engineering Notes, New York, p. 2537, Apr. 1988.

4. EARL, M. J. Information systems strategy formulation. Critical issues in information systmes research. New York: John Wiley \& Sons, 1987.

5. ALBERTIN, A. L. Administração de informática: um estudo sobre seus fatores críticos de sucesso no setor bancário privado naclonal. São Paulo: FEA/USP, 1993 (dissertação de mestrado).

6. ROCKART, J. F. Chief executives define their own data needs. Harvard Business Review, Boston, v. 57, n. 2, p. 81-93, Mar./Apr. 1979. 
A escolha do setor bancário deve-se pelas suas características, que o apontam como um dos que mais se utiliza da informática para sua operacionalizaçāo e estratégia competitiva. Particularmente nos grandes bancos, essa utilizaçāo é, de fato, muito acentua$\mathrm{da}$, sendo este o segmento analisado no trabalho.

\section{A METODOLDGIA DE ESTUDO}

A metodologia utilizada para o estudo foi a de Estudo de Múltiplos Casos, conforme descrita por Yin?. A escolha de estudo de casos deveu-se ao fato de a questão básica da pesquisa ser do tipo "como" e "por quê", e a escolha de múltiplos casos, à impossibilidade de atender a essas condiçōes com o estudo de um único caso.

Os casos estudados sāo um subconjunto das instituiçôes bancárias privadas nacionais. Esse subconjunto foi formado por três casos, que estāo entre os maiores bancos privados nacionais.

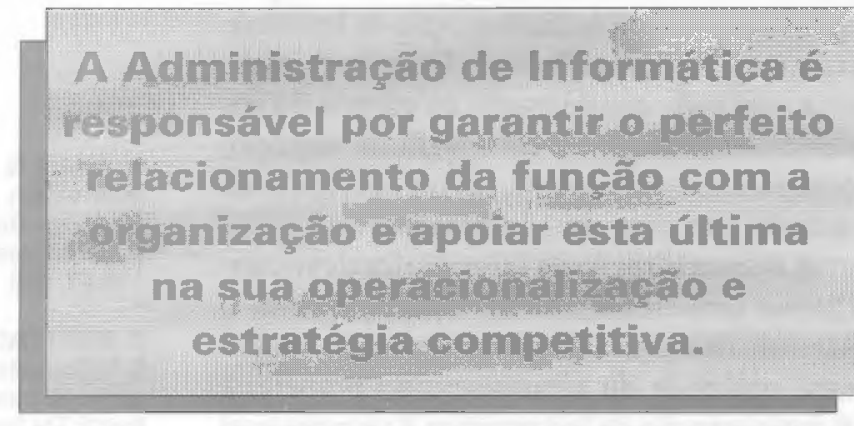

7. YIN, R. K. Case study research: design and methods. Newburry Park, CA, USA: Sage Publications, 1989.

8. SYNNOT, W. R. The information weapon. New Yark: John Wiley \& Sons, 1987.

9. CASH, J. I. MCFARLAN, E. W. MCKENNEY, J. L. Corporate information systems management: the issues facing senior executives. Homewood, IL: Richard D. Irwin, 1992.
Os casos foram estudados mediante entrevistas com perguntas que pediam respostas abertas, dado que com esse tipo de pergunta procura-se obter o maior número de informaçōes, quer sejam literalmente expressas ou não. Esta escolha também se deve ao fato de que não se queria estudar um fator único, mas sim a relaçāo de fatores considerados críticos na Administração de Informática daquelas organizaçōes. Outro motivo da escolha dessa metodologia foram as críticas à teoria dos FCS, principalmente em relação às dificuldades desuaidentificaçāo por uma única pessoa.

Foram realizadas entrevistas com pelo menos três niveis hierárquicos da $\mathrm{AI}$ (Área de Informática), entre eles seu principal executivo, seu superior imediato, um gerente de nível hierárquico médio e um analista. A atenção voltou-se para a área de desenvolvimento de sistemas por esta ser considera- da como a que possui maior "participaçāo" dos usuários, que tem maior contato com estes e que tem as funçóes menos processuais da AI, principalmente com a evoluçāo tecnológica atual e a preocupaçāo funcional e de negócio tẫo enfatizada.

Também foram realizadas entrevistas com representantes de usuários para que fossem obtidas informaçóes do seu ponto de vista e avaliaçāo sobre qualidade de serviço, de relacionamento e de atendimento de suas necessidades.

O estudo e as conclusōes utilizaram, como quadro de referência, vários estudos referentes à administração e à TI. Particularmente, foram utilizadas as funçóes de administraçăo como orientaçăo à coleta e à análise de informaçōes, bem como a elaboraçāo de conclusōes. As funçōes são planejamento, organizaçāo, pessoal, direção e controle.

\section{OS BANCOS E A ADMINISTRAÇ̃̃O DE INFORMÁTICA}

A análise dos casos permite algumas conclusōes sobre os bancos e a sua Administração de Informática, entre elas que os bancos se enquadram na Era de Informação ${ }^{8}$, como já era esperado. As características que confirmam essa análise são:

- seu principal execulivo tem uma preocupaçäo em adquirir uma boa visáo do negócio;

- esses executivos estão subordinados à alta administraçāo;

- a utilização da informática está relacionada com a estratégia competitiva dos bancos;

- os bancos fazem altos investimentos em informática;

- existe uma constante busca da integração tecnológica;

- existe uma constante busca da integração da AI com a organização.

Em relação ao marketing-mix do produto de informática9 ${ }^{9}$, os bancos começam a direcionar o seu foco para o futuro:

- manutenção de produtos velhos com desafios da obsolescência;

- concentração em produtos pequenos e médios, em detrimento de grandes projetos;

- projetos com benefícios intangiveis;

- pressão para a utilização de novas tecnologias.

As fontes são internas e externas, porém existe uma certa predominância das primei- 
ras. A economia de competência ainda é um desafio para a gerência de pessoal, e não ficou clara a predominância de sistemas nãoestruturados.

$\mathrm{O}$ ambiente da informática ${ }^{10}$, nos bancos é, sem dúvida, estratégico, dada as suas dependências da perfeita funcionalidade das atividades de SI e das aplicaçōes em desenvolvimento.

Os estágios de crescimento de processamento de dados ${ }^{11}$ dos bancos também sāo semelhantes. Os bancos se encontram no estágio de integração, com a passagem do ponto de transição e início de visualização do estágio de Administração de Dados, devido à:

- grande utilização de banco de dados;

- grande utilização de terminais interativos;

- busca da integração dos sistemas;

- procura de controle e planejamento voltados para a gerência de informação;

- participação cada vez maior dos usuários;

- utilização de uma administração de dados aperfeiçoada;

- busca de soluções em novas plataformas.

O estado de administração da computação ${ }^{12}$ nos bancos é uma combinação entre serviço e controle. Quanto ao de competência, que existiu no passado, há uma preocupação no sentido de evitá-lo. O estado de serviço é encontrado no relacionamento e no atendimento aos usuários para a priorização de projetos pequenos, manutenções localizadas etc. O de controle é encontrado no estudo e aprovação de grandes projetos, altos investimentos e nos planejamentos a médio e longo prazos.

As situações descritas acima são coerentes entre si. Numa organização na qual o ambiente de informática é estratégico, o estágio de crescimento de processamento de dados deve se situar após o ponto de transição, e a combinação dos estados de administração da computação deve ter uma parte considerável do estado de serviço.

A automação bancária envolve a da rede nacional de agências, que está bem servida; postos externos de atendimento, com rede própria ou de terceiros; e entrega eletrônica de serviços. A automação bancária é o redesenho dos processos do negócio dos bancos e implica um alinhamento estratégico.

No estudo, a importância do aspecto social foi sempre matéria de observação em qualquer uma das funçōes. É claro que esse componente deve ser considerado como determinante na Administração de Informática.

A imagem da AI também foi estudada, e é caracterizada:

- pela idéia de que AI é uma "caixa-preta";

- pela formação de parcerias com os usuários;

- pelo poder que a AI tem devido à tecnologia que domina;

- pelo cumprimento de planos elaborados pela própria AI;

- pelo comportamento ético e isento;

- pela proximidade da organização e do próprio negócio.

\section{As funções administrativas}

A função de planejamento é considerada como a mais importante e é básica para as demais. Na Administração de Informática, foram identificados dois níveis: o estratégico, razoavelmente bem conduzido, e o operacional, com deficiências na elaboração e implementação. Tanto o planejamento quanto sua implementação são considerados como os maiores problemas para a AI. O quadro 1 apresenta um resumo das observações para a função planejamento.

Na função organização foi identificada uma grande preocupação com a proximidade ou distância da AI em relação à organização. As áreas usuárias alegam que os problemas referentes ao relacionamento com a $\mathrm{AI}$ deve-se à sua distância da organização. Por seu lado, a AI também sente esse problema, mas o atribui à falta de participação do usuário. Tanto a AI quanto as áreas usuárias consideram que a estrutura organizacional da primeira é responsável por muitos dos seus problemas de relacionamento e de desempenho de atendimento. $\mathrm{O}$ quadro 2 apresenta um resumo das observações para a função organização.

Na função pessoal identificou-se que os aspectos técnicos continuam tendo mais relevância que os gerenciais, e essa situação contribui para o relacionamento deficiente da AI com a organização. Os aspectos gerenciais e sociais começam a ser percebidos como críticos, porém continua a existir grande pressão para a utilização de novas tecnologias. $O$ quadro 3 apresenta um resumo das observaçōes para a função pessoal.

Na função direção identificou-se uma forte tendência de utilização de administração por colegiado, interna e externamente à AI. Para esta última, a principal preocupação é em relaçāo à gerência de nível médio, dada a
10. MCFARLAN, E. W. MCKENNEY, L., PYBURN, P. The information archipelago - plotting a course. Harvard Business Review, Boston, v. 61, n. 1, p. 145-56, Jan./Feb. 1983.

11. NOLAN, R.L. Managing the crises in data processing. Harvard Business Review, Boston, v. 57, n. 2, p. 115-26, Mar./Apr. 1979.

12. KRAEMER, K. L. Managing information systems. Handbook of public administration. New York: John Wiley \& Songs, 1989. 


\begin{tabular}{|c|c|}
\hline Guadro 1 & $\begin{array}{l}\text { das observaçóes para a } \\
\text { çăo planejamento }\end{array}$ \\
\hline Fator & Consideraçóes \\
\hline 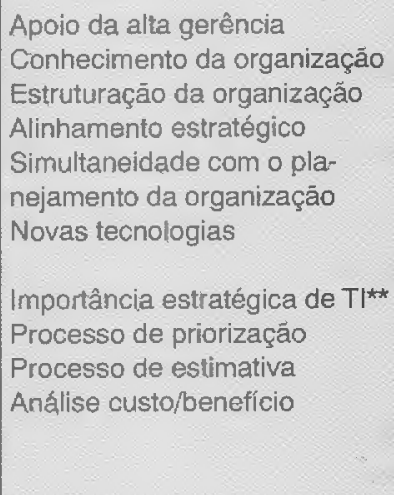 & $\begin{array}{l}\text { Crítico } \\
\text { Năo-crítico, natural para a Al* } \\
\text { Não-crítico, independente para Al } \\
\text { Crítico } \\
\text { Não-crítico, o alinhamento trata } \\
\text { dessa questāo } \\
\text { Não-crítico, considerado na função } \\
\text { pessoal } \\
\text { Não-crítico, visão já adquirida } \\
\text { Crítico } \\
\text { Grítico } \\
\text { Não-crítico, considerado como } \\
\text { parte do processo de estimativa } \\
\text { e da funçāo controle }\end{array}$ \\
\hline
\end{tabular}

\begin{tabular}{|c|c|}
\hline Quadro 2 & $\begin{array}{l}\text { observaçōes para a função } \\
\text { organizaçáo }\end{array}$ \\
\hline Fator & Consideraçöes \\
\hline $\begin{array}{l}\text { Parcerias internas e externas } \\
\text { Estrutura organizacional } \\
\text { Participaçāo na organização }\end{array}$ & $\begin{array}{l}\text { Nāo-crítico, considerado como tema } \\
\text { a ser estudado } \\
\text { Grítico } \\
\text { Crítico }\end{array}$ \\
\hline
\end{tabular}

Quadro 3 Resumo das observaçōes para a função
pessoal

\begin{tabular}{|c|c|}
\hline Quadro 4 & $\begin{array}{l}\text { observaçöes para a funçăo } \\
\text { direçáo }\end{array}$ \\
\hline Fator & Consideraçōes \\
\hline $\begin{array}{l}\text { Participaçăo da alta gerência } \\
\text { Gerência de nivel médio }\end{array}$ & $\begin{array}{l}\text { Nāo-crítico, considerado na } \\
\text { função planejamento } \\
\text { Crítico }\end{array}$ \\
\hline
\end{tabular}

Quadro 5
\begin{tabular}{|l|l|}
\hline Fator & $\begin{array}{c}\text { Resumo das observaçōes para a funçáo } \\
\text { controle }\end{array}$ \\
\hline $\begin{array}{l}\text { Controle de desempenho e } \\
\text { qualidade }\end{array}$ & Crítico \\
\hline
\end{tabular}

sua deficiência de formaçāo. O quadro 4 apresenta um resumo das observaçōes para a funçāo direção.

$\mathrm{Na}$ função controle, confirmou-se que continua com carências conceituais em relação às atividades e produtos nāo-tangíveis ou menos operacionais. $\mathrm{O}$ controle das demais tem tido sucesso, mas necessita de aperfeiçoamento. O quadro 5 apresenta um resumo das observaçōes para a função controle.

\section{FATORES CRÍTICOS DE SUCESSO DA ADMINISTRAÇÃO DE INFORMÁTICA}

Os FCS da Administraçăo de Informática foram identificados a partir das conclusōes dos casos e têm sido revistos em constantes e recentes pesquisas e estudos.

\section{Planejamento}

A funçāo planejamento é a principal e é determinante para a AI. É a base para as demais e a sua execução e cumprimento contribui para a formação de um histórico de competência e para o sucesso da Administraçāo de Informática, além de garantir a consistência dos SI com a organizaçāo.

Assim, o planejamento, por si só, já pode ser considerado como um FCS para a AI, devido à sua relevância, sua condiçăo de base para as demais funçōes, as características e as evoluçóes do ambiente tecnológico e de negócios,

De fato, o planejamento e sua implementação efetiva é o problema mais sério enfrentado pela AI.

O planejamento da $\mathrm{AI}$, na prática, é dividido em dois níveis. O primeiro considera os grandes projetos, altos investimentos, mudanças e inovaçōes tecnológicas profundas. Dada toda a pressão ambiental, de negócios e tecnologia, esse nível tem recebido bastante atençāo e há uma constante preocupação com a melhoria de seu processo.

O segundo considera os projetos menores e as manutençốes de SI, tendo como características mais marcantes as mudanças constantes, novas tecnologias já disponíveis e identificação de novas necessidades quase que diariamente. Nesse nível, residem os maiores problemas daAI, sejam internos ou no relacionamento com a organizaçăo. Também nesse nivel, exige-se da AI que sejam analisadas as várias alternativas de soluções que considerem as tecnologias disponíveis.

Os FCS identificados na função planejamento devem ser considerados nos doís ní- 
veis, porém o segundo deve receber uma atenção especial, dada a situação atual e a importância que o primeiro recebe naturalmente, devido ao nível hierárquico envolvido.

O primeiro FCS identificado na função planejamento é o apoio da alta gerência, representado pela sua participação tanto no planejamento da AI como na sua administração. Esse apoio deve:

- criar um ambiente propício à visão da informática como arma da estratégia competitiva;

- garantir acesso às informações da organização, tal como do seu planejamento estratégico;

- propiciar uma visão global da organização;

- determinar as diretrizes da AI;

- participar no processo de priorização;

- garantir os investimentos aprovados;

- facilitar a administração de mudanças nos planejamentos, através de solução de conflitos de recursos, estudos de viabilidades, comunicação de importância e impactos das mudanças.

Albertin ${ }^{13}$ estudou os efeitos negativos da falta desse apoio da alta gerência, apresentando, inclusive, a necessidade da coerência entre o tipo de apoio da alta gerência, o estado de crescimento de processamento de dados e o estado de administração de computação.

O segundo é o alinhamento estratégico entre a AI e a organização, para a garantia de coerência com as estratégias, prioridades e estrutura organizacional. Esse alinhamento inclui as dimensões de negócio, da TI e dos ambientes internos e externos. Ele também visa a evitar uma visão parcial das necessidades da organização, a criação de uma AI voltada somente para seu ambiente e a subutilização dos seus recursos. Henderson e Venkatraman ${ }^{14}$ apresentaram um modelo de alinhamento estratégico que considera essas quatro dimensões e suas relações.

O terceiro é o processo de priorização, que deve ser totalmente baseado no alinhamento estratégico e aplicado nos dois níveis de planejamento. Os fatores deste processo devem incluir:

- objetivos do negócio;

- estratégias do negócio;

- benefícios financeiros;

- benefícios intangíveis;
- automação de processos;

- controles internos;

- importância técnica.

Os participantes desse processo devem ser a alta gerência e os níveis hierárquicos gerenciais das áreas usuárias e da AI.

O quarto é o processo de estimativa dos esforços necessários para o atendimento dos pedidos, que é base para os seus planejamentos. Nesse processo devem ser utilizadas técnicas que propiciem uma melhoria constante das estimativas, através de informações de histórico, acompanhamento e realimentação posterior. $\mathrm{O}$ grande desafio é a identificação e adaptação para o ambiente real de uma técnica que se torne exeqüível: a técnica de histórico é muito utilizada por ser de fácil aplicação e devido à baixa rotatividade do pessoal da AI, mas não existe a prática de realimentação do processo com as informações das execuções dos planos. A importância das estimativas está na obtenção do custo para a análise de viabilidade e na elaboração de planos confiáveis, que formarão um histórico de competência favorável ou não.

Para a melhoria deste processo é necessário aumentar a qualidade e a quantidade de informações sobre justificativas de pedidos para Informática e de estudos de custos e benefícios.

\section{Organização}

O apoio da alta gerência também deve ser considerado na organização, uma vez que o estabelecimento da estrutura organizacional pode facilitar ou não esse apoio. Essa estrutura deve facilitar a participação ativa da alta gerência e dos usuários e uma melhor comunicação entre todos os participantes, independentemente do nível hierárquico. As duas formas estabelecidas com esta visão são a posição hierárquica da $\mathrm{AI}$ próxima à alta gerência da organização e os comitês e comissões com a participação das áreas usuárias e da AI.

O primeiro FCS identificado na função organização é o estabelecimento de uma estrutura organizacional bem definida quanto às responsabilidades, atribuiçōes, canais de comunicação e participação ativa de todos os niveis.
13. ALBERTIN, A. L. Administração de informática e a organizacão. RAE - Revista de Administração de Empresas, São Paulo, v. 34, n. 6, p. 60-72, nov./ dez. 1994.

14. HENDERSON, J. C. e VENKATRAMAN, N. Strategic aligment: A framework for strategic information technology management. Cambridge, USA: MIT Sloan School of Management, 1989. 
Essa estrutura deve considerar a criação de parcerias com terceiros, visando a uma melhor adequação entre recursos e necessidades, mas essa utilização deve ser matéria de procedimentos e diretrizes específicos. A terceirização pode ser utilizada, também, como forma de criar um ambiente mais profissional e competitivo na AI.

Essa estrutura deve ainda facilitar a aquisição, assimilação, disseminação e utilização de novas tecnologias, sob pena de tornar-se, ou pelo menos passar a imagem de, uma área voltada a tecnologias tradicionais e distante das soluçōes mais modernas e ágeis.

O segundo FCS é a participação na organização, traduzido na proximidade com as áreas usuárias, com a organização e com o ambiente do próprio negócio. Essa participação visa:

- à priorização coerente com a organização;

- à definição dos problemas de forma mais completa;

- à especificação de soluções para os problemas reais, conjunta com os usuários;

- à adequação da "velocidade" da AI com a organização;

- à obtenção de uma visão do mercado e dos clientes da organização;

- ao estabelecimento de uma postura voltada também para o negócio e não apenas para assuntos técnicos.

\section{Pessoal}

As exigências de capacitação do pessoal da AI têm mudado nos últimos anos, forçando-a a voltar-se para o negócio e para o relacionamento entre os ambientes internos e externos, além do aspecto técnico. Além disso, a qualidade de pessoal técnico e gerencial deve superar as possiveis falhas e problemas do planejamento e da organização.

O primeiro FCS identificado na função pessoal é o desenvolvimento gerencial dos participantes da AI. Ele deve considerar:

- as necessidades de contatos constantes com os usuários;

- a negociação de prioridades e prazos;

- a obtenção de compromissos entre os envolvidos;

- a administração do próprio trabalho, devido à autonomia exigida por suas características;

- a especificação de problemas e soluções que envolvem aspectos sociais;

- a identificação e obtenção de requisitos e informações.
O desenvolvimento gerencial do pessoal da AI faz parte dos fatores motivadores mais relevantes para seus participantes.

O segundo FCS relaciona-se às novas tecnologias. Abrange a aquisição, assimilação, disseminação e utilização de novas tecnologias, seja através de prospecção interna ou externa. O domínio, mínimo que seja, de novas tecnologias visa a possibilitar que a $\mathrm{AI}$ ofereça à organização soluções mais ágeis e coerentes com sua realidade, inclusive no planejamento. Por seu lado, as áreas usuárias são expostas - através da imprensa, de contatos com o mercado e conhecimentos pessoais às novas tecnologias, exigindo da $\mathrm{AI}$ a sua consideração e tornando-se capaz de questionar as soluções oferecidas por ela. Além disso, o acesso a novas tecnologias também é um fator altamente motivador para os participantes da AI.

Esses dois fatores criam um desafio para a AI. Seus responsáveis precisam garantir que seu pessoal tenha sempre um perfeito domínio das tecnologias que estão sendo utilizadas, mas também adquiram competência nas novas. Além disso, exige-se da AI que seus participantes não tenham uma postura essencialmente técnica, devendo voltar-se cada vez mais para o negócio da organização e os aspectos gerenciais. O equilíbrio dessas três capacitações deve ser mantido.

\section{Direção}

A ênfase em treinamento e desenvolvimento de pessoal na AI foi, até pouco tempo atrás, bastante técnica. Além das considerações feitas na função pessoal, essa situação afeta a função direção, devido à pouca preparação dos seus participantes para assumir posições gerenciais. Isso se percebe nos níveis hierárquicos gerenciais mais baixos, que não garantem essa preparação mas exigem de imediato que se desempenhem atividades de coordenação e liderança.

A comunicação interna da $\mathrm{AI}$ e com a organização tem se tornado parte necessária dos processos da AI, sendo considerados os dois sentidos dessa comunicação.

A direção da AI é marcada por uma grande autonomia, tanto de assuntos técnicos quanto funcionais, sendo que essa situação ocorre mais em decorrência da falta de recursos e habilidade dos gerentes de nível médio do que por uma regra estabelecida.

O FCS identificado na função direção é a gerência de nível médio, quanto à sua preparação e participação ativa nos processos da AI. Nisso está a garantia de que os demais 
participantes terão a orientação e as informaçōes necessárias para a execuçāo de suas tarefas. As atividades mais críticas são:

- comunicação;

- orientação técnica e gerencial;

- coordenaçāo interna e externa de atividades;

- delegação de responsabilidades e autoridade;

- relacionamento com as áreas usuárias e as demais da AI;

- avaliaçāo profissional dos subordinados;

- ligaçāo entre os níveis hierárquicos inferiores e superiores.

\section{Controle}

O controle na AI tem sido exercido principalmente nas atividades estruturadas e mais operacionais, devido à ênfase técnica da área e à facilidade de estabelecer os procedimentos de controle para esse tipo de atividade, sendo considerado insuficiente nas atividades pouco estruturadas e que têm muitos serviços nảo-planejados, como, por exemplo, desenvolvimento e manutençâo de SI.

Essa situação guarda certa incoerência com o valor econômico de TI e seus processos. O controle é baseado na delegação das responsabilidades, dos gerentes para os analistas e das áreas usuárias para a área de Informática.

O FCS identificado na funçäo controle é o estabelecimento de controles de desempenho e qualidade dos produtos e das atividades, tão eficientes como os já estabelecidos para as atividades operacionais. Esses controles também devem ter critérios não-técricos, tais como satisfação dos usuários e dos clientes, adequação, nível de utilização etc. E devem ser claros e estabelecidos num nível que năo se tornem obstáculos para o desempenho das atividades.

Os controles devem ser suficientes para:

- evitar ocorrências de erros após a liberaçảo do serviço solicitado;

- garantir o cumprimento do alinhamento estratégico;

- realimentar o processo de planejamento;

- garantir a qualidade dos SI, e nảo só a qualidade técnica;

- evitar a ocorrência de retrabalho;

- verificar a validade dos custos estimados e os benefícios declarados antecipadamente.

\begin{tabular}{|c|c|}
\hline Quadro 6 & $\begin{array}{l}\text { Resumo dos Fatores Críticos de Sucesso } \\
\text { da Adiministraçấo de Informática }\end{array}$ \\
\hline Função & Fator Grítica de Sucesso \\
\hline $\begin{array}{l}\text { Planejamentẹ } \\
\text { Organização } \\
\text { Pessoal } \\
\text { Direção } \\
\text { Controle }\end{array}$ & $\begin{array}{l}\text { Apoio da alta gerência } \\
\text { Alinhamento estratégico } \\
\text { Processo de priorizaçăo } \\
\text { Processo de estimativa } \\
\text { Estrutura organizacional } \\
\text { Participação na organização } \\
\text { Desenvolvimento gerencial } \\
\text { Capacitação em novas tecnologias } \\
\text { Gerência de nível médio } \\
\text { Controle de desempenho } \\
\text { e qualidade }\end{array}$ \\
\hline
\end{tabular}

\section{CONCLUSÃO}

Os FCS estão diretamente relacionados ao contexto no qual a Administração de Informática vem sendo realizada. São o resultado da situaçāo de negócios e de TI, tanto no nível interno quanto no externo à organização, e todas as suas relaçôes possíveis.

Os FCS na Administração de Informática visam, num primeiro nível, a assegurar seu sucesso enquanto área dentro da organização à qual deve servir, e, num segundo nível, a garantir o sucesso das organizações que consideram a TI como um de seus fatores.

Assin, os FCS identificados, conforme recentes estudos, podem ser entendidos como sendo aplicáveis em outros setores além do bancário, principalmente nas organizaçōes que tenham características semelhantes quanto ao estágio de crescimento, ao estado de administração e ao ambiente de informática.

Os fatores estão relacionados com as funçōes de administraçāo desempenhadas. Porém, como as funçōes, seus produtos e seus componentes estão intimamente relacionados, o FCS de uma função interfere nas demais. O quadro 6 apresenta o resumo dos fatores de acordo como as funçōes de administraçāo.

O estudo e o tratamento desses FCS devem ser realizados continuamente pelas organizaçōes, sob pena do não-aproveitamento do potencial da TI e não-garantia do sucesso da Administração de Informática. Mesmo que os fatores não șe alterem, sua importância relativa e conseqüente prioridade podem mudar. $\square$

\section{3}

